\title{
Endocrine Studies of the Untreated Progeny of Thyroidectomized Rats
}

\author{
J. L. BAKKE, ${ }^{33}$ N. L. LAWRENCE, S. ROBINSON, AND J. BENNETT \\ Pacific Northwest Research Foundation, Seattle, Washington, USA
}

\section{Extract}

Experiments were conducted to assess late and persistent endocrine changes in the progeny of rats born of and/or nursed by thyroidectomized ( $T x$ ) dams. Forty-five female rats were radiothyroidectomized several weeks before mating with normal males, and compared with the progeny of 26 control females. In all, 248 progeny were studied when adult.

Tx dams had significantly reduced fertility $(87 \%$ of controls), increased pup (11\% versus 0 ) and maternal mortality ( $27 \%$ versus 0 ), and smaller litters (6.5 versus 11.8 pups/litter).

It was shown that the offspring of thyroidectomized female rats had delayed eye opening ( 15.3 versus 14.3 days), smaller weaning $(40.4$ versus $54.4 \mathrm{~g})$ and adult body weights ( 230 versus $260 \mathrm{~g}$ ), smaller pituitary glands (12.2 versus $14.0 \mathrm{mg})$, and enlarged thyroid glands ( 14.2 versus $12.4 \mathrm{mg}$ ). Ovarian and testicular weights were decreased ( 73.9 versus $83.7 \mathrm{mg}$ and 3.2 versus $3.6 \mathrm{~g}$, respectively). The serum thyroid stimulating hormone (TSH) concentrations were increased from 53.8 to $84.4 \mu \mathrm{U} / \mathrm{ml}$ in the males. The pituitary TSH contents were not significantly altered, and the serum TSH response to thyrotropin releasing hormone (TRH) was normal. These persistent effects differed from the late effects of both fetal and neonatal hypothyroidism and neonatal underfeeding. Cross-fostering experiments showed that the diminished weaning weights were the result of the pups being nursed by the hypothyroid dams. The increased nursing mortality and the pituitary and thyroidal changes were the result of prenatal influences produced by the hypothyroid dams, since being nursed by a normal foster dam did not prevent them. The persistently enlarged thyroid glands and the elevated serum TSH in the male offspring of thyroidectomized dams suggested a permanent alteration in the set point of pituitary-thyroid regulation as the consequence of maternal hypothyroidism.

\section{Speculation}

It is speculated that the intrauterine environment provided by the pregnant hypothyroid mother produces permanent alterations in endocrine regulatory mechanisms in the offspring. It is suggested that the transplacental transfer of fetal thyroxine $\left(T_{4}\right)$ to the hypothyroid mother places a burden on the fetal pituitary-thyroid axis that permanently alters its function in these progeny. We have shown previously that during a critical perinatal period, $\mathrm{T}_{4}$ excess or deficiency can permanently alter hypothalamo-pituitary regulatory function in the offspring.

Whether or not maternal hypothyroidism can cause fetal or congenital hypothyroidism has been an enigma for many years. It has been stated that if a woman has given birth to two cretins she has an increased chance of producing a cretin in the next pregnancy (10). However, even severely hypothyroid mothers usually deliver normal infants (21), and most mothers of cretins are euthyroid throughout their pregnancy. For these reasons, it has been necessary to consider other explanations for the sporadic congenitally hypothyroid infant. Current theory proposes that genetic factors may predominate, although it is likely that the transplacental transfer of circulating autoantibodies or other unidentified intrauterine thyrocytoxic factors might cause damage to the fetal thyroid $(9,18)$. In one series $(22), 9$ of 20 instances of congenital hypothyroidism due to dyshormonogenesis had evidence for an autosomal recessive inheritance.

Stabenau and Pollin (29) studied 23 pairs of adult monozygotic twins and showed a significant correlation between birth weight and adult protein bound iodine (PBI). They suggest that genetic similarity was not as important in determining the PBI as individual nongenetic differences which may be the result of intrauterine factors. Unfortunately, these studies have not been pursued (personal communication). Man (23) reported that "maternal hypothyroxinemia, both in areas of adequate and inadequate iodine intake, may be a significant factor in retardation and neurologic deficits of progeny." This observation has not been confirmed, but it raises the possibility that maternal hypothyroidism during pregnancy may cause significant abnormalities in the progeny. Study of this possibility has received remarkably little attention by experimental endocrinologists. Carr et al. (10) thyroidectomized 14 pregnant dogs and studied the pups by measuring serum PBI, thyroidal ${ }^{131}$ I uptake, and thyroid weight, and concluded that they did not differ from the pups born of euthyroid dogs. However, their data revealed an increase in pup mortality and in some instances the surviving pups grew subnormally. One, killed at 108 days, was weak and runted and had a PBI of $2.0 \mu \mathrm{g} / 100 \mathrm{ml}$.

Studies in man (11) and sheep $(12,28)$ indicate that only negligible quantities of thyroid hormone are transferred across the placenta in either direction. However, this is probably not true of the rat. Although thyroidectomy of the pregnant rat did not alter the fetal butanol extractable iodine (BEI), it did cause a further decrease in the fetal BEI when the fetal thyroid gland was also ablated (17). Geloso and Bernard (16) concluded that some maternal hormone passes through the placenta into the fetal rat. Galton (14) and Gray and Galton (19) confirmed and extended this observation by showing a reduction in fetal PBI in Tx dams and they showed that injecting the dam with $\mathrm{T}_{4}(2-5 \mu \mathrm{g} / 100 \mathrm{~g}$ body wt $/ 24 \mathrm{hr}$ ) caused an increase in fetal PBI and suppression of fetal thyroid function.

There are also two pertinent studies on the effects of hypophysectomy in the pregnant rat on her fetuses studied at term. Nataf and Chaik off (27) found no effect of hypophysectomy on fetal thyroid weight or ${ }^{131} \mathrm{I}$ distribution among the iodinated amino acids in the fetal thyroid tissue. Hamburgh et al. (20) agreed that the fetal thyroid at term was not affected by maternal hypophysectomy. Neither studied pups after birth.

In view of these generally negative reports, we were surprised to find that the untreated offspring of hypothyroid mother. rats showed significant abnormalities.

\section{METHODS AND MATERIALS}

Female Sprague-Dawley rats, 55 days old, were placed on a low iodine diet for 3 days before a $0.5 \mathrm{mCi}$ subcutaneous dose of ${ }^{131} \mathrm{I}$ 
for Tx. Three weeks later, five random control and five $T x$ animals were killed under light pentobarbital anesthesia to test the completeness of thyroidectomy. Examination of tracheas of $\mathrm{Tx}$ animals revealed no thyroid tissue. Trunk blood was collected individually for serum $\mathrm{T}_{4}$ determinations (26). The control animals had $5.83 \pm 0.53 \mu \mathrm{g} / 100 \mathrm{ml}$ and the Tx animals had $2.95 \pm 0.11$ $(P<0.001)$. One month later groups of Tx and normal control females were bred with normal males for the first experiment. In the second experiment, 2 months after radiothyroidectomy, blood samples were taken from seven randomly selected animals for TSH assays to confirm the success of radiothyroidectomy. Serum TSH concentrations averaged $124 \pm 11 \mathrm{mU} / 100 \mathrm{ml}$; levels were 20 times normal. Approximately 2 weeks later, the rats were bred for 16 days. Two breeding combinations were used: experimental, two normal males caged with six or seven Tx females; control, two normal males caged with six normal females. Males were rotated every 4 or 5 days to minimize the effect of a possibly subfertile male. When pups were born they were sorted to make up litters of 10 males or 10 females. Because of the prolonged breeding period, it was not possible to determine whether or not gestational age was altered. The separation of the sexes avoided the unequal nursing aggressiveness manifested by the different sexes. In order to assist lactation in the first experiment, Tx dams received $\mathrm{T}_{4}, 1 \mu \mathrm{g} / 100 \mathrm{~g}$ body weight the first day postpartum and $0.5 \mu \mathrm{g} / 100 \mathrm{~g}$ body weight the second day, and none thereafter. In the second experiment, all Tx dams with pups were given $1 \mu \mathrm{g} \mathrm{T}_{4} / 100 \mathrm{~g}$ body weight every third day until the pups were 18 days old. In our colony, this dose of $T_{4}$ has been demonstrated to be well below the replacement requirement of $2-3 \mu \mathrm{g} / 100 \mathrm{~g}$ body weight $/ 24 \mathrm{hr}$, although in this experiment we did not measure $\mathrm{T}_{4}$ or $\mathrm{TSH}$ during lactation to verify this. Cross-fostered pups were placed with foster dams when 1 day old and left until weaning. All pups weighing less than $30 \mathrm{~g}$ at 21 days of age were left with their dams until they reached this weight.

The nursing pups were examined daily for eye opening, which was designated as the day both eyes were open. At weaning, all rats were housed two to a cage and maintained on Purina laboratory chow and tap water ad libitum and kept in quiet quarters with a controlled temperature $\left(24 \pm 0.5^{\circ}\right)$ and diurnal lighting $(14 \mathrm{hr}$ light). In the first experiment the day of vaginal opening was noted; once it had occurred smears were obtained daily by vaginal lavage and microscopically examined in the fresh state without staining. Estrous cycle length was designated as the number of days between fully cornified smears. This was done for three cycles when the rats were about 50 days of age. At maturity, groups of untreated male and female offspring were anesthesized with sodium pentobarbital and received injections via the femoral vein with 100 or $200 \mathrm{ng}$ synthetic TRH/100 g body weight (31). Blood samples were obtained $15 \mathrm{~min}$ later for TSH assay. An additional group of female rats from the first experiment received $0.00625 \%$ propylthiouracil (PTU) drinking water for 7 days before killing to measure their response to PTU challenge.

Female parents were killed at 195 days of age and tracheas of Tx animals were examined for possible thyroidal remnants. None were found in any rat.

When killed, the rats were anesthetized lightly with sodium pentobarbital intraperitoncally and decapitated as soon as they were drowsy. All rats were killed between 1 and $4 \mathrm{pm}$ to avoid circadian variations in TSH secretion (1). The sera or plasma samples were frozen individually for TSH radioimmunoassay. The radioimmunoassay was performed with the reagents kindly supplied by the National Institutes of Health Rat Pituitary Hormone Distribution Program. The standard was NIAMD-Rat TSH-RP-1 stated to contain 0.22 USP (bovine) U/mg. The thyroids, ovaries, uteruses, testes, ventral prostate, adrenals, and pituitaries were removed and weighed individually on the appropriate size RollerSmith torsion balance. Stalk median eminence fragments weighing approximately $20 \mathrm{mg}$ were homogenized in buffer and frozen for assay. All organ weights were recorded as wet weights and presented as means \pm SE. Relative organ weights were also calculated and expressed per $100 \mathrm{~g}$ body weight. Pituitary glands were homogenized individually in glass homogenizers at $4^{\circ}$ in isotonic Krebs-Ringer phosphate buffer at $\mathrm{pH} 7.4,1$ pituitary $/ 3 \mathrm{ml}$ and further diluted in $1 \%$ bovine serum albumin buffer and frozen for later TSH assay.

\section{RESULTS}

Table 1 shows the late effects of radiothyroidectomy. A group of 15 control and 15 Tx females were killed when 195 days old. It may be seen that the hypothyroid animals had significant diminution in pituitary and body weight. The adrenals were reduced markedly in size, more than proportional to the reduced body weight, and the ovaries were significantly smaller. Although the uterine weights were reduced, the difference was not significant. The pituitary TSH was reduced significantly and the serum TSH was markedly elevated to $1,006 \pm 105 \mu \mathrm{U} / \mathrm{ml}$, confirming the hypothyroid state of the Tx group.

Table 2 shows the results of mating control and Tx dams under the conditions of the second experiment. These observations were

Table 1. Endocrine effects of radiothyroidectomy (Tx) in female rats $^{1}$

\begin{tabular}{lcc}
\hline & Control & Tx \\
\hline Number & 15 & 15 \\
Body wt $(\mathrm{g})$ & $311 \pm 5$ & $214 \pm 24^{2}$ \\
Pituitary wt $(\mathrm{mg})$ & $16.84 \pm 0.60$ & $13.12 \pm 0.38^{2}$ \\
Thyroid wt $(\mathrm{mg})$ & $17.0 \pm 0.4$ & 0 \\
Adrenal wt $(\mathrm{mg})$ & $61.2 \pm 2.1$ & $34.7 \pm 1.4^{2.3}$ \\
Ovarian wt $(\mathrm{mg})$ & $78.7 \pm 3.9$ & $64.0 \pm 2.6^{2}$ \\
Uterine wt $(\mathrm{mg})$ & $572 \pm 32$ & $495 \pm 33$ \\
Pituitary TSH $(\mathrm{mU} /$ gland $)$ & $293 \pm 36$ & $160 \pm 9^{2}$ \\
SME TSH $(\mu \mathrm{U} / \mathrm{gland})$ & $94 \pm 14$ & $135 \pm 19$ \\
Serum TSH $(\mu \mathrm{U} / \mathrm{ml})$ & $54.1 \pm 10.6$ & $1,006 \pm 105^{2}$ \\
\hline
\end{tabular}

${ }^{1}$ Means \pm SE for group of females used as dams in experiment II; killed when 195 days old. TSH: thyroid stimulating hormone; SME TSH: TSH in hypothalamus.

${ }^{2} P<0.01$.

${ }^{3} P<0.01$, significance when relative weights were used.

Table 2. Fertility and nursing success of thyroidectomized (Tx) female rats ${ }^{1}$

\begin{tabular}{lcccc}
\hline & $\begin{array}{c}\text { Control } \\
\text { dams }\end{array}$ & $\%$ & $\begin{array}{c}\text { Tx } \\
\text { dams }\end{array}$ & $\%$ \\
\hline Pregnancy rate & $11 / 11$ & 100 & $26 / 30$ & 87 \\
Maternal mortality $^{2}$ & $0 / 11$ & 0 & $7 / 26$ & 27 \\
Pup birth mortality $^{3}$ & $0 / 119$ & 0 & $13 / 123$ & 11 \\
Average litter size $^{4}$ & $10.8 \pm 1.2$ & & $6.5 \pm 0.3^{5}$ & \\
Range of litter size $_{\text {Pup nursing mortality }}$ & $2-15$ & & $4-9$ & \\
$\quad$ With normal dams & $0 / 39$ & 0 & $5 / 40$ & 13 \\
$\quad$ With Tx dams & $2 / 40$ & 5 & $20 / 64$ & 31 \\
\hline
\end{tabular}

${ }^{1}$ Breeding exposure was 16 days. Five or six females were caged with two males. To promote lactation it was necessary to give the thyroidectomized dams $1 \mu \mathrm{g}$ thyroxine/ $100 \mathrm{~g}$ body wt every 3 days until pups were 18 days old.

${ }^{2}$ Maternal death during parturition.

${ }^{3}$ Pup death at birth (excluding the seven dams that died).

${ }^{4}$ Mean \pm SE.

${ }^{5} P<0.01$.

${ }^{6}$ Pup mortality between birth and weaning. Total number adjusted at birth to stated number. 
not obtained in the first experiment. Whereas all of the controls became pregnant, only $87 \%$ of the $T x$ females became pregnant. Of the Tx females $27 \%$ died during parturition, whereas none of the controls did. Of the pups born to Tx dams, $11 \%$ were dead at birth, whereas none of the control pups were. The litter size was significantly smaller $(P<0.01)$ in the Tx dams. After birth, when all of the pups were distributed either to control or foster dams for nursing, it may be seen that the offspring of control dams had no mortality if fostered by a normal dam but that there was a $5 \%$ mortality in those nursed by a Tx dam. In contrast, the offspring of the Tx dams showed a $13 \%$ mortality when nursed by normal dams, and a $31 \%$ mortality when nursed by Tx dams.

Table 3 shows the results of the first experiment. It may be seen that in both sexes the offspring of hypothyroid dams had delayed eye opening and diminished weaning and final body weights $(P<$ $0.01)$. Puberty, first estrus, and estrous cycle lengths were not affected. In both sexes the pituitary weights were significantly smaller, the thyroid weights were significantly larger, and the gonadal weights were smaller. The adrenal weights were reduced in the male offspring, but not in the females. Pituitary and stalk median eminence TSH contents were not affected significantly but the serum TSH was elevated significantly in the males. The serum $\mathrm{T}_{4}$ concentrations were not abnormal in the small group tested. The TRH response was measured in the adult male offspring and found to be normal. The response to PTU challenge was measured in the adult females and the goiters were significantly larger, relatively, in the offspring of the TX dams. The serum TSH was also elevated, but the differences were not statistically significant.
The number of offspring of each sex available for measuring TRH and PTU response was limited so it was necessary to use the females for one measurement and the males for the other.

In an effort to separate the effects of impaired nursing care by Tx dams from the prenatal intrauterine effects of hypothyroidism, a cross-fostering experiment was performed as presented in Table 4. Experiment II differs from experiment $I$ in that the nursing thyroidectomized dams were given a small dose of $\mathrm{T}_{4}$ every 3 days to ameliorate, but not correct, the hypothyroidism and to permit better nursing. It may be seen that in this experiment eye opening was no longer delayed. However, the reduced weaning weight was present in the pups that were nursed by a Tx dam, regardless of whether their prenatal environment had been euthyroid or hypothyroid. When the offspring of Tx dams were killed at 124 days of age, they had smaller pituitary glands and larger thyroids in both sexes, regardless of whether or not they were nursed by a normal or a Tx dam. The adrenal weight was reduced significantly in the control males that were nursed by a Tx dam and was significantly increased in the female offspring of Tx dams who were nursed by a control dam. Testicular weights were significantly smaller in all groups when compared with controls. Ovarian weights were not affected, nor were the prostate and uterine weights. The pituitary TSH contents were not abnormal in any group. However, in the male offspring, the serum TSH concentrations were significantly elevated in all three experimental groups, confirming the results in experiment I. The females did not show this difference in either experiment. The serum TSH response 15 min after the injection of TRH was similar in all groups of the same sex, the greater

Table 3. Experiment 1: The untreated $F_{1}$ offspring of normal and thyroidectomized $(T x)$ dams ${ }^{1}$

\begin{tabular}{|c|c|c|c|c|}
\hline & \multicolumn{2}{|c|}{ Female offspring } & \multicolumn{2}{|c|}{ Male offspring } \\
\hline & Control & Tx dam & Control & Tx dam \\
\hline Eye opening (days) & $14.3 \pm 0.1$ & $15.3 \pm 0.2^{3}$ & $14.9 \pm 0.2$ & $15.2 \pm 0.3$ \\
\hline Weaning wt $(\mathrm{g})$ & $54.4 \pm 1.0$ & $40.4 \pm 1.6^{3}$ & $52.4 \pm 1.1$ & $42.2 \pm 1.3^{3}$ \\
\hline Final wt (g) & $260 \pm 5$ & $230 \pm 6^{3}$ & $442 \pm 8$ & $374 \pm 11^{3}$ \\
\hline \multicolumn{5}{|l|}{ Cycle length (days) ${ }^{4}$} \\
\hline Minimum & $3.7 \neq 0.1$ & $3.7 \pm 0.1$ & & \\
\hline Maximum & $4.5 \pm 0.1$ & $4.6 \pm 0.1$ & & \\
\hline Pituitary wt (mg) & $14.03 \pm 0.49$ & $12.17 \pm 0.62^{5}$ & $11.48 \pm 0.40$ & $10.03 \pm 0.29^{3}$ \\
\hline Thyroid wt (mg) & $12.4 \pm 0.5$ & $14.2 \pm 0.5^{5.6}$ & $13.9 \pm 0.4$ & $15.3 \pm 1.0^{6}$ \\
\hline Adrenal wt (mg) & $61.0 \pm 2.1$ & $58.4 \pm 2.5$ & $45.7 \pm 0.6$ & $39.5 \pm 1.3^{3}$ \\
\hline Serum TSH $(\mu \mathrm{U} / \mathrm{ml})$ & $52.0 \pm 17.8$ & $38.5 \pm 7.7$ & $53.8 \pm 5.7$ & $84.4 \pm 6.7^{3}$ \\
\hline Serum $T_{4}(\mu \mathrm{g} / 100 \mathrm{ml})^{7}$ & $4.24 \pm 0.45$ & $4.60 \pm 0.56$ & $6.16 \pm 0.44$ & $6.06 \pm 0.64$ \\
\hline \multicolumn{5}{|l|}{$\mathrm{TRH}^{8}$ or PTU ${ }^{9}$ response: } \\
\hline Pituitary TSH (mU) & $51 \pm 5$ & $45 \pm .7$ & $277 \pm 31$ & $258 \pm 12$ \\
\hline SME TSH $(\mu \mathrm{U})$ & $73 \pm 21$ & $116 \pm 37$ & $255 \pm 64$ & $214 \pm 54$ \\
\hline Serum TSH $(\mu U / \mathrm{ml})$ & $187 \pm 20$ & $213 \pm 33$ & $758 \pm 50$ & $810 \pm 69$ \\
\hline Thyroid wt (mg) & $27.0 \pm 0.8$ & $29.0 \pm 1.6^{6}$ & & \\
\hline
\end{tabular}

${ }^{1}$ Males were 94 days old when killed and females were 100 days old. TSH: thyroid stimulating hormone; SME TSH: TSH in hypothalamus; ${ }_{4}$ : thyroxine; TRH: thyrotropin releasing hormone; PTU: propylthiouracil.

${ }^{2}$ At weaning there were 128 rats; 40 controls of each sex and 24 of each sex from Tx dams.

${ }^{3} P<0.01$.

${ }^{4}$ Three cycles were measured when rats were approximately 50 days old.

${ }^{s} P<0.05$.

${ }^{8} P<0.01$, significance when relative weights were used.

${ }^{7}$ Serum $\mathrm{T}_{4}$ determinations were made on groups of five.

${ }^{8} \mathrm{TRH}$ response in males 8 min after $200 \mathrm{ng} \mathrm{TRH} / 100 \mathrm{~g}$ body wt intravenously $(n=12)$.

${ }^{9}$ PTU response in females; $0.00625 \%$ PTU drinking water for 7 days before kill $(n=12)$. 
Table 4. Experiment II: Cross fostering untreated offspring of normal and thyroidectomized (Tx) mothers ${ }^{1}$

\begin{tabular}{|c|c|c|c|c|c|c|c|c|}
\hline & \multicolumn{4}{|c|}{ Female offspring } & \multicolumn{4}{|c|}{ Male offspring } \\
\hline & $\mathrm{CoCo}^{2}$ & $T \times T x^{2}$ & $\operatorname{CoT} x^{2}$ & $\mathrm{TxCO} \mathrm{O}^{2}$ & $\mathrm{CoCo}^{2}$ & $\mathrm{Tx} T x^{2}$ & $\operatorname{CoT} x^{2}$ & $\mathrm{TxCo}^{2}$ \\
\hline Final number & 15 & 14 & 14 & 10 & 14 & 17 & 14 & 15 \\
\hline Eye opening (days) & $15.1 \pm 0.2$ & $14.6 \pm 0.2$ & $14.7 \pm 1.2$ & $15.0 \pm 0.2$ & $15.5 \pm 0.2$ & $15.0 \pm 0.2$ & $15.2 \pm 0.2$ & $14.9 \pm 0.3$ \\
\hline Weaning wt (g) & $45 \pm 1$ & $31 \pm 1^{3}$ & $28 \pm 2^{3}$ & $45 \pm 1$ & $44 \pm 1$ & $33 \pm 1^{3}$ & $32 \pm 1^{3}$ & $49 \pm 2$ \\
\hline Final wt $(\mathrm{g})$ & $261 \pm 7$ & $251 \pm 4$ & $253 \pm 4$ & $272 \pm 5$ & $431 \pm 8$ & $432 \pm 7$ & $414 \pm 8$ & $448 \pm 20$ \\
\hline Pituitary wt (mg) & $14.68 \pm 0.54$ & $12.79 \pm 0.44^{4,6}$ & $14.02 \pm 0.54$ & $12.53 \pm 0.61^{4,6}$ & $11.95 \pm 0.27$ & $10.41 \pm 0.28^{3.5}$ & $11.47 \pm 0.36$ & $10.95 \pm 0.37^{4,6}$ \\
\hline Thyroid wt (mg) & $13.1 \pm 0.5$ & $15.1 \pm 0.6^{4.6}$ & $13.4 \pm 0.5$ & $14.8 \pm 0.7^{4}$ & $16.7 \pm 0.6$ & $18.0 \pm 0.8$ & $17.4 \pm 0.8$ & $19.8 \pm 0.8^{3,6}$ \\
\hline Adrenal wt (mg) & $61.8 \pm 1.8$ & $66.5=2.9$ & $57.5 \pm 1.8$ & $72.7 \pm 3.1^{3,5}$ & $45.9 \pm 7.7$ & $47.1 \pm 1.7$ & $38.6 \pm 3.8^{4,6}$ & $43.3 \pm 1.2^{5}$ \\
\hline Gonad wt $(\mathrm{mg}, \mathrm{g})$ & $80.0 \pm 2.6$ & $76.9 \pm 4.7$ & $79.6 \pm 2.6$ & $79.8 \pm 5.9$ & $3.90 \pm 0.10$ & $3.16 \pm 0.12^{3.6}$ & $3.37 \pm 0.08^{3}$ & $3.61 \pm 0.08^{4,6}$ \\
\hline Uterine or prostate wt $(\mathrm{mg})$ & $540 \pm 31$ & $514 \pm 24$ & $482 \pm 25$ & $530 \pm 26$ & $485 \pm 25$ & $575 \pm 39$ & $502 \pm 25$ & $537 \pm 26$ \\
\hline Pituitary TSH (mU/gland) & $259 \pm 21$ & $273 \pm 16$ & $215 \pm 14$ & $223 \pm 17$ & $255 \pm 19$ & $279 \pm 19$ & $273 \pm 16$ & $278 \pm 29$ \\
\hline SME TSH $(\mu \mathrm{U} /$ gland $)$ & $103 \pm 16$ & $83 \pm 12$ & $108 \pm 12$ & $97 \pm 6$ & $143 \pm 8$ & $158 \pm 13$ & $106 \pm 17$ & $111 \pm 14$ \\
\hline Serum TSH $(\mu \mathrm{U} / \mathrm{ml})$ & $41.5 \pm 7.6$ & $40.1 \pm 6.4$ & $36.9 \pm 5.4$ & $47.4 \pm 7.4$ & $40.4 \pm 6.2$ & $58.8 \pm 4.9^{4}$ & $66.0 \pm 9.4^{4}$ & $61.8 \pm 6.4^{4}$ \\
\hline 15 min after $\mathrm{TRH}^{7}$ & $461 \pm 29$ & $431 \pm 65$ & $436 \pm 65$ & $553 \pm 100$ & $770 \pm 102$ & $728 \pm 42$ & $727 \pm 132$ & $766 \pm 92$ \\
\hline Serum $\mathrm{T}_{4}(\mu \mathrm{g} / 100 \mathrm{ml})^{8}$ & $3.50 \pm 0.41$ & $4.19 \pm 0.18$ & & & $5.83 \pm 0.34$ & $4.94 \pm 0.34$ & & \\
\hline
\end{tabular}

${ }^{1}$ These rats were killed at 124 days of age. All comparisons are with the CoCo group of the same sex. TSH: thyroid stimulating hormone; SME TSH:

TSH in hypothalamus, $\mathrm{TRH}$ : thyrotropin releasing hormone; $\mathrm{T}_{4}$ : thyroxine.

${ }^{2} \mathrm{CoCo}$ : offspring of a control dam nursed by a control foster dam; CoTx: offspring of a control dam nursed by a Tx foster dam; TxCo: offspring of a Tx dam nursed by a control foster mother; TxTx: offspring of Tx dam nursed by a Tx foster mother.

${ }^{3} P<0.01$.

${ }^{4} P<0.05$.

${ }^{5} P<0.05$, significance when relative weights were used.

${ }^{6} P<0.01$, significance when relative weights were used.

${ }^{7}$ Dose of $100 \mathrm{ng} / 100 \mathrm{~g}$ body wt injected into femoral vein.

${ }^{8}$ Serum $T_{4}$ determinations were done on seven rats in each group. 
response being, as usual, in males. The few measurements of serum $\mathrm{T}_{4}$ made on half of each group indicated failed to show any abnormalities.

\section{DISCUSSION}

When the results of the two experiments are compared, there is general agreement. The delayed eye opening, which was highly significantly in the first experiment, was not present in the second, probably because of the better lactation provided by the Tx dams in this experiment. These dams received $T_{4}$ injections every 3 days throughout the nursing period. The dose used was sufficient to ameliorate, but not correct, the hypothyroidism as indicated by the significantly reduced weaning weights seen in Table 4 in both normal pups and the offspring of Tx mothers that were nursed by Tx foster mothers. The ameliorating effect of the treatment used in the second experiment may also account for the more normal final body weights seen in all groups. In both experiments there were highly significant decreases in adult pituitary weights and increases in thyroid weight in the offspring of Tx dams, regardless of whether or not they had normal nursing foster dams. This was accompanied by a significant increase in serum TSH concentration in the male offspring in both experiments. Thus, these effects must be attributable to prenatal maternal hypothyroidism. In addition, it may be noted that being nursed by a normal dam did not prevent a significant neonatal pup mortality during nursing for the progeny of Tx dams.

It should be emphasized that the smaller pituitary glands and larger thyroids were highly significant changes whether expressed in absolute terms or corrected for differences in body weight; i.e., the relative weights were significantly different in 8 of 12 comparisons. The reason for these goiters is uncertain but it suggests that something about the maternal hypothyroid intrauterine environment stimulated the fetus to produce more TSH, at least temporarily, resulting in a larger thyroid gland. Fukuda et al. (13) have shown that iodine-deficient pregnant mother rats have fetuses which develop goiters; however, in our experiments the dams' rat chow was rich in iodine, so this explanation may be excluded. Hamburgh et al. (20) have reported that when groups of hypophysectomized and intact dams were given PTU from the 15 th day of gestation until term, fetal goiters developed in both groups. However, when they also injected $\mathrm{T}_{4}$ into the dams, they found that the dose of $T_{4}$ required to inhibit goiter development in fetuses was reduced in the hypophysectomized dams as compared with intact pregnant rats. Such increased sensitivity to $T_{4}$ inhibition of goiter growth is also characteristic of rats with hypothalamic lesions (24); thus, maternal hypothyroidism may have some adverse effect on fetal hypothalamic development, possibly mediated by transplacental passage of maternal TRH. Since TRH is a small molecule that probably crosses the placental barrier, one must consider the possibility that $T x$ dams have an elevated serum TRH concentration that might stimulate fetal TSH secretion. Against this conjecture, however, is the report (25) that hypothyroidism has no effect on serum TRH concentrations.

We have shown previously that the brief exposure of the fetus to PTU during the last 3 days of gestation or to PTU injected into the neonate during the first 4 days of life will result in a permanently enlarged thyroid gland. and a permanent decrease in pituitary and

Table 5. Comparisons of late consequences of perinatal treatments ${ }^{1}$

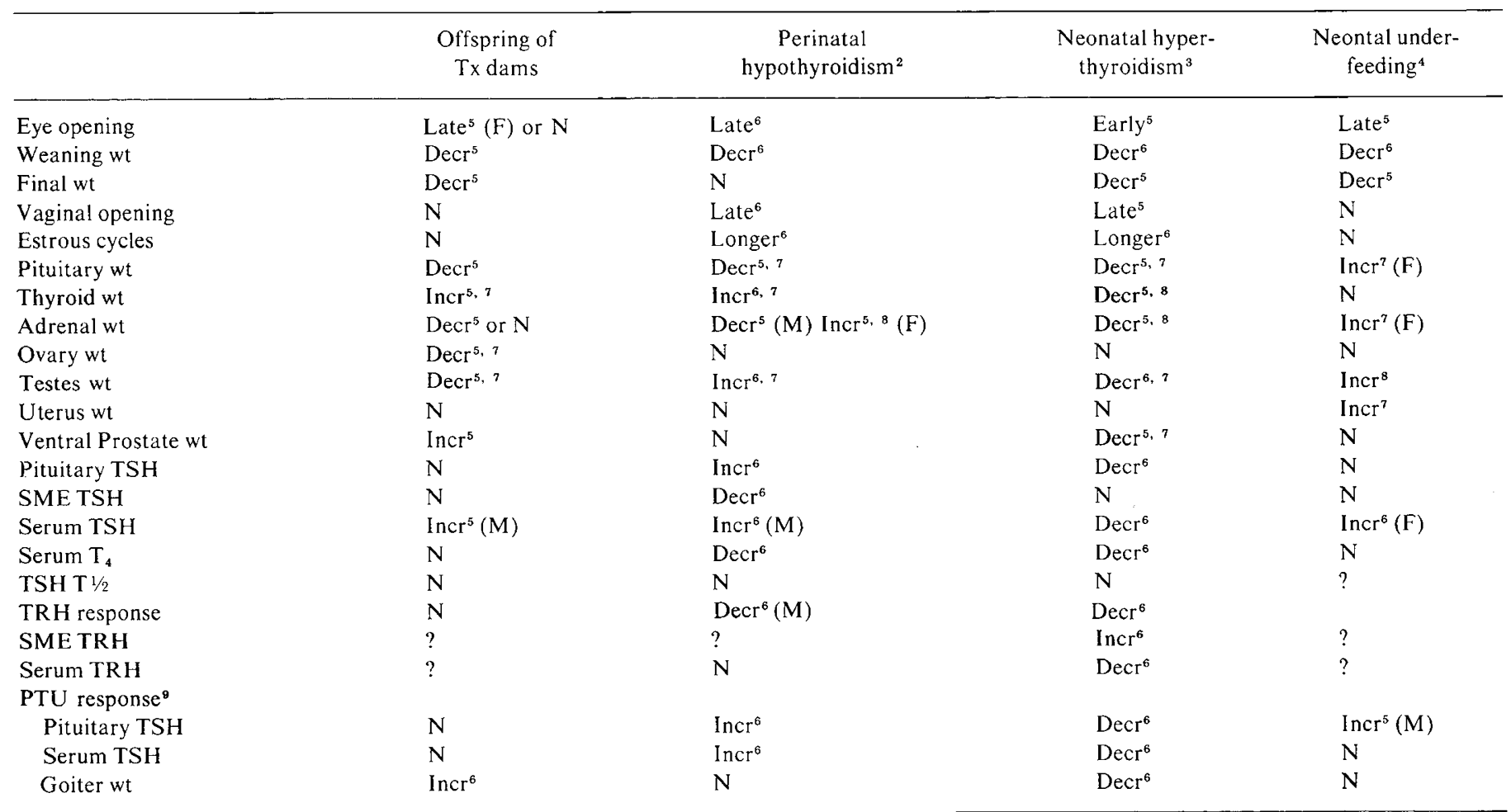

${ }^{1}$ A representative summary of numerous experiments. Tx: thyroidectomized; N: normal, i.e., differing by less than $10 \%$ (not significant); Decr: decrease; Incr: increase; TSH: thyroid stimulating hormone; TRH: thyrotropin releasing hormone; SME TSH: TSH in hypothalamus; PTU: propylthiouracil; M: males only; F: females only; no designation: sexes were not different.

${ }^{2}$ See References 4 and 7.

${ }^{3}$ See References 2, 5, 7, and 8.

${ }^{4}$ See References 6, 7, and 15 .

${ }^{5} P<0.01$.

${ }^{6} P<0.05$.

${ }^{7} P<0.01$, significance of relative weight differences (per $100 \mathrm{~g}$ body $\mathrm{wt}$ ).

${ }^{8} P<0.05$, significance of relative weight differences (per $100 \mathrm{~g}$ body $\mathrm{wt}$ ).

${ }^{9}$ PTU response was only done in female offspring of $T x$ mothers. 
adrenal weight (4). These rats also show an increase in pituitary and serum TSH concentration, a decrease in $\mathrm{T}_{4}$, and a blunted response to TRH (7). Table 5 summarizes these changes. Since these changes are the result of a brief period of perinatal hypothyroidism one may speculate that the Tx hypothyroid dam induces some degree of hypothyroidism in the fetus which provokes a response by the independent fetal endocrine system. As mentioned in the introductory section, the rat may be an unusual species in its transplacental transfer of significant amounts of thyroid hormone. Possibly in our experiments, the markedly hypothyroid dams not only failed to supply the usual amount of thyroid hormone to the fetus, but also placed an increased burden on the fetus to provide some thyroid hormone to the maternal circulation. Gray and Galton's (19) data support this possibility. Even if this transfer is small in terms of maternal needs, it might be relatively large in fetal terms. This activation of the fetal TSH system during this critical phase of development might produce permanent alterations in endocrine functions analogous to those seen after perinatal hypothyroidism (4) and neonatal hyperthyroidism $(2,5,7,8,15)$.

Since it may be presumed that the severely hypothyroid dams were unable to provide normal nutrition for their offspring it is important to compare the results presented here with the results of neonatal underfeeding. The offspring of Tx dams differ from those who suffered neonatal underfeeding in several significant regards. Neonatal underfeeding produced rats with increased pituitary weights and normal thyroid and ovarian weights (6). The females had an increase in serum TSH but both sexes showed normal pituitary TSH contents. The adrenal weights were increased in females. These differences are summarized in Table 5. It is concluded that, although perinatal malnutrition may have been present in the offspring of hypothyroid dams, the offspring showed changes that cannot be ascribed to neonatal malnutrition. We have not studied the effects of prenatal maternal malnutrition, however.

The elevated serum TSH in the male offspring is unexplained. The normal pituitary TSH content, serum $\mathrm{T}_{4}$ concentration, and normal response to TRH all preclude the presence of primary hypothyroidism in the offspring. Possibly there was a mild thyroidal defect in this group which threatened to cause hypothyroidism and this was prevented by an adequate compensatory increase in TSH secretion. The mechanism by which a hypothyroid dam caused these changes in her offspring deserves further study. Although the physiologic significance of TSH in the hypothalamus is unclear (3), it was noted that it was not abnormal in any of the experiments presented here.

Lastly, there remains the possibility that some of the results may have been due to nonspecific irradiation damage. In view of the dose of ${ }^{131} \mathrm{I}$ and the long delay before mating this seems unlikely and there are no reports of such changes resulting from irradiation of female rats either before or during pregnancy.

Until the mechanism by which maternal hypothyroidism alters fetal development is elucidated, it is premature to speculate about any relevance of these findings to the human hypothyroid mother. However, these studies certainly offer indirect support for full thyroid hormone replacement therapy in any pregnant hypothyroid woman and careful evaluation of her progeny for pituitarythyroidal and gonadal defects.

\section{SUMMARY}

It has been shown that the offspring of thyroidectomized female rats have delayed eye opening, smaller weaning and adult body weights, smaller pituitary glands, and enlarged thyroid glands. Adrenal and testicular weights were decreased and serum TSH concentrations were increased in the males. The pituitary TSH contents were slightly increased and the serum TSH response to TRH was normal. These persistent effects differed from the late effects of both perinatal hypothyroidism and neonatal underfeeding. Cross-fostering experiments show that the diminished weaning weights were the result of nursing of pups by hypothyroid dams.
The pituitary and thyroidal changes were the result of prenatal influences produced by the hypothyroid dams since being nursed by a normal foster dam did not prevent them. The persistently elevated serum TSH in the male offspring of thyroidectomized dams suggests a permanent alteration in the set point of pituitarythyroid regulation as the consequence of the maternal hypothyroidism.

\section{REFERENCES AND NOTES}

1. Bakke, J. L., and Lawrence, N.: Circadian periodicity in thyroid stimulating hormone titer in the rat hypophysis and serum. Metabolism, 14: 841 (1965).

2. Bakke, J. L., and Lawrence, N.: Persistent thyrotropin insufficiency following neonatal thyroxin administration. J. Lab. Clin. Med., 67: 477 (1966).

3. Bakke, J. L., and Lawrence, N.: Thyrotropin (TSH) in the rat stalk-median eminence. Neuroendocrinology, 2: 315 (1967).

4. Bakke, J. L., Gellert, R. J., and Lawrence, N. L.: The persistent effects of perinatal hypothyroidism on pituitary, thyroidal and gonadal functions. J. Lab. Clin. Med., 76: 25 (1970).

5. Bakke, J. L., Lawrence, N., and Wilber, J. F.: The late effects of neonatal hyperthyroidism upon the hypothalamic-pituitary-thyroid axis in the rat. Endocrinology, 96: 406 (1974).

6. Bakke, J. L., Lawrence, N. L., Bennett, J., and Robinson, S.: Late effects of neonatal undernutrition and overnutrition on pituitary, thyroidal and gonadal function. Biol. Neonate, in press.

7. Bakke, J. L., Lawrence, N. L., Bennett, J., and Robinson, S.: Endocrine syndromes produced by neonatal hyperthyroidism, hypothyroidism or altered nutrition and effects seen in their untreated progeny. In: D. A. Fisher and G. N. Burrow: Maternal-Fetal-Thyroid Function, Proceedings of the Kroc Foundation Symposium, No. 3 (Raven Press, New York, 1975).

8. Bakke, J. L., Lawrence, N. L., Bennett, J., and Robinson, S.: The late effects of neonatal hyperthyroidism upon the feedback regulation of TSH secretion in rats. Endocrinology, in press.

9. Blizzard, R. M., Chandler, R. S., Landing, B. H., Pettit, M. D., and West, C. D.: Material autoimmunization to thyroid as a probable cause of anthyrotic cretinism. N. Engl. J. Med., 263: 327 (1960).

10. Carr, E. A., Jr., Beierwaltes, W. H., Raman, G., Dodson, V. N., Tanton, J., Betts, J. S., and Stambaugh, R. A.: The effect of maternal thyroid function on fetal thyroid function and development. J. Clin. Endocrinol. Metab., 19: 1 (1959).

11. Dussault, J., Row, V. V., Lickrish, G., and Volpé, R.: Studies of serum triiodothyronine concentration in maternal and cord blood: Transfer of triiodothyronine across the human placenta. J. Clin. Endocrinol. Metab., 29: 595 (1969)

12. Erenberg, A., Omori, K., Oh, W., and Fisher, D. A.: The effect of fetal thyroidectomy on thyroid hormone metabolism in maternal and fetal sheep. Pediat. Res., 7: 870 (1973).

13. Fukuda, H., Panton, P., Kutas, M. and Greer, S.: Comparison of fetal pituitary-thyroid maturation in rats fed a high (HID) or low-iodine (LID) diet [Abstract]. (Program of the 56th Meeting of the Endocrine Society, No. 365 1974).

14. Galton, V. A.: Thyroxine metabolism and thyroid function in the pregnant rat. Endocrinology, 82: 282 (1968).

15. Gellert, R. J., Bakke, J. L., and Lawrence, N. L.: Delayed vaginal opening in the rat following pharmacologic doses of $T_{4}$ administered during the neonatal period. J. Lab. Clin. Med., 77: 410 (1971).

16. Geloso, J. P., and Bernard, G.: Effects de l'ablation de la thyroide maternelle ou foetale sur le taux des hormones circulantes chez le foetus de rat. Acta Endocrinol., 56: 561 (1967).

17. Geloso, J. P., Hemon, P., Legrand, J., Legrand, C., and Jost, A.: Some aspects of thyroid physiology during the perinatal period. Gen. Comp. Endocrinol., 10: 191 (1968).

18. Goldsmith, R. E., McAdams, A. J., Larsen, P. R., MacKenzie, M., and Hess, E. V.: Familial autoimmune thyroiditis: Maternal-fetal relationship and the role of generalized autoimmunity. J. Clin. Endocrinol. Metab., 37: 265 (1973).

19. Gray, B., and Galton, V. A.: The transplacental passage of thyroxine and foetal thyroid function in the rat. Acta Endocrinol., 75 : 725 (1974).

20. Hamburgh, M., Sobel, E, H., Koblin, R., and Rinestone, A.: Passage of thyroid hormone across the placenta in intact and hypophysectomized rats. Anat. Rec., 144: 219 (1962).

21. Hodges, R. E., Hamilton, H. E., and Keettel, W. C.: Pregnancy in myxedema. Amer. Med. Ass. Arch. Intern. Med., 90: 863 (1952).

22. Mäenpää, J.: Congenital hypothyroidism: Aetiological and clinical aspects. Arch. Dis. Childhood, 47: 914 (1972).

23. Man, E. B.: Thyroid function in pregnancy and infancy. Clin. Lab. Sci., 3: 203 (1972).

24. Martin, J. B., Boshans, R., and Reichlin, S.: Feedback regulation of TSH secretion in rats with hypothalamic lesions. Endocrinology, 87: 1032 (1970).

25. Montoya, E., and Wilber, J. F.: Studies of thyrotropin-releasing hormone (TRH) physiology by radioimmunoassay: Effects of triiodothyronine $\left(\mathrm{T}_{3}\right)$ and thyroxine $\left(\mathrm{T}_{4}\right)$ [Abstract]. (Program of the 56th Meeting of the Endocrine Society, No. 19, 1974).

26. Murphy, B. E. P., and Pattee, C. J.: Determination of thyroxine utilizing the property of protein-binding. J. Clin. Endocrinol., 24: 187 (1964). 
27. Nataf, B. M., and Chaikoff, I. L.: Effect of hypophysectomy of the pregnant rat on ${ }^{131}$ I metabolism of the fetal thyroid gland. Endocrinology, 73: 518 (1963).

28. Robin, N. I., Selenkow, H. A., Fang, V. S., Refetoff, S., Paisecki, G Rauschecker, H., and Jackson, B. T.: Bidirectional thyroxine exchange in pregnant sheep. Hormones, 3: 235 (1972).

29. Stabenau, J. R., and Pollin, W.: Adult protein-bound iodine and maturity at birth in monozygotic twins. J. Clin. Endocrinol. Metab., 28: 693 (1968).

30. ICN Pharmaceuticals, Inc., Cleveland, Ohio.
31. Kindly provided by Abbott Laboratories, North Chicago, III.

32. This work was supported by Grant no. AM-05638-14 from the National Institute of Arthritis, Metabolic and Digestive Diseases of the National Institutes of Health and by the Pacific Northwest Research Foundation.

33. Requests for reprints should be addressed to: J. L. Bakke, M.D., Pacific Northwest Research Foundation, 1102 Columbia St., Seattle, Wash. 98104 (USA).

34. Accepted for publication May 19, 1975
Adrenergic blockade diabetes

glucagon growth hormone $\alpha$ - and $\beta$-receptors sympathetic activity

\title{
Effect of Adrenergic Blockade on Glucagon and Growth Hormone Secretion in Normal and Diabetic Children
}

\author{
MARK A. SPERLING(39) AND SANDRA VOINA \\ Department of Pediatrics, UCLA-Harbor General Hospital, Torrance, California, USA
}

\section{Extract}

Studies were conducted in four normal and six diabetic children to assess the role of adrenergic blockade on basal and arginine-stimulated growth hormone and glucagon secretion. Each subject had, on three separate occasions, infusion of arginine alone or in conjunction with $\alpha$ (phentolamine) or $\beta$ (propranolol) adrenergic blockade. Clinically, there was evidence of adequate blockade by each agent. Basal hormone growth levels were not significantly different in the two groups $(1.3 \pm 0.2$ to $2.1 \pm 1.0 \mathrm{ng} / \mathrm{ml}$ in normal subjects; $3.0 \pm 1.1$ to $6.0 \pm 3.1 \mathrm{ng} / \mathrm{ml}$ in diabetics (mean \pm 1 SEM)) but the peak growth hormone after arginine was significantly greater in the diabetic children than control subjects $\mathbf{3 4 . 3} \pm$ 7.2 versus $12.3 \pm 3.1$ ); in both groups $\alpha$-blockade suppressed the growth hormone response, whereas $\beta$-blockade had no significant effect. Basal glucagon concentrations were similar in both groups $(147 \pm 31$ to $214 \pm 21 \mathrm{pg} / \mathrm{ml}$ in normal subjects; $100 \pm 20$ to $124 \pm 17 \mathrm{pg} / \mathrm{ml}$ in diabetics on three different occasions) despite the coexistent hyperglycemia of the diabetics. Neither basal nor maximally stimulated glucagon secretion was significantly affected by $\alpha$ or $\beta$ blockade in the juvenile diabetic or control children. The results suggest that sympathetic overactivity via $\alpha$ receptors may contribute to the hypersecretion of growth hormone in juvenile diabetes and that the $\alpha$ or $\beta$ adrenergic receptor alone does not appear to modulate basal or arginine stimulated glucagon secretion.

\section{Speculation}

Sympathetic overactivity, documented in poorly controlled juvenile diabetic subjects may, via $\alpha$ receptors, be one of the mechanisms responsible for growth hormone hypersecretion in these subjects. Although the evidence suggesting a role for adrenergic stimuli in modulating glucagon secretion is compelling, the relative hypersecretion of glucagon in juvenile diabetics in response to arginine does not seem to be predominately influenced by either $\alpha$ or $\beta$ adrenergic receptors alone.

It has been firmly established that the adrenergic nervous system, through the release of catecholamines, is capable of modulating insulin and growth hormone secretion $(2,17,22,26$, $28,29,36)$. Recent data also implicate a role for adrenergic agonists in stimulating glucagon secretion (18). Anatomic and histologic studies demonstrate sympathetic nerve endings directly on the pancreatic islet $(9,18)$, and stimulation of the splanchnic sympathetic nerve in dogs (25), cats (8), and calves (4), causes a rise in glucagon secretion. In man, a variety of stressful situations $(3,10,30)$ as well as direct infusion of epinephrine $(12)$ result in a rise in plasma glucagon concentration. However, unlike insulin and growth hormone, where there is uniform agreement that the adrenergic effects are mediated via activation of adrenergic receptors which are inhibitory or stimulatory, the precise role of these receptors in modulating glucagon secretion remains uncertain. Activation of both $\alpha$ or $\beta$ adrenergic receptors has been reported to either stimulate or inhibit glucagon secretion $(7,11,13$, $14,16,18-20,23,36)$, and contradictory results have been reported within the same species, despite similarities in experimental design $(11,13,16,23)$.

To date few studies have focused on factors affecting glucagon secretion in normal and diabetic children. The present investigation in children was therefore undertaken in order to ascertain the effects of $\alpha$ or $\beta$ adrenergic blockade on basal and argininestimulated glucagon as well as growth hormone secretion. Because patients with juvenile diabetes have been reported to have inappropriately elevated glucagon and growth hormone concentrations in the basal and stimulated state $(32,34)$, it was anticipated that an effect of $\alpha$ or $\beta$ adrenergic blockage might be more apparent in this group.

\section{METHODS}

\section{SUBJECTS AND PROCEDURES}

Six juvenile diabetics, aged 11-16 years, and four normal children, 13-16 years, were each studied on three separate occasions with an intravenous arginine infusion, given either alone or in conjunction with $\alpha$ (phentolamine) or $\beta$ (propranolol) adrenergic blockade. At least 3 days elapsed between each study. 